\title{
Microbial growth behind tiles in bathrooms
}

\author{
Gunilla Bok $^{1 *}$ and Pernilla Johansson ${ }^{1}$ \\ ${ }^{1}$ RISE Research Institutes of Sweden, Built Environment, Box 857, S50115 Borås, Sweden
}

\begin{abstract}
Studies investigating microbial diversity in buildings have been performed mainly through the study of dust collected from e. g. floors and door frames and on moisture damaged building materials. A great diversity of mould fungi has been found and the fungus flora is dominated by the genera Aspergillus and Penicillium. The building materials targeted in this specific study were sampled on the back of ceramic tiles from bathroom walls and floors. Furthermore, two different analyses were used to investigate to which degree this specific environment was supportive of microbial growth. Microbial findings were detected in $48 \%$ of the specimens from the spots exposed to liquid water in the bathrooms. To our knowledge, the microbial occurrence in this type of environment has not previously been investigated..
\end{abstract}

\section{Introduction}

Walls and floors in wet rooms are exposed to free water either directly when water sprinkles from the shower against the wall/floor or indirectly by water splash. When the surface layers of walls and floors are covered with ceramic tiles these tiles are fastened to the wall/floor with cement-based tile adhesive. The tile adhesive, in turn, is applied to a waterproof membrane which stops further water transport into the wall/floor. In a tiled wet room liquid water is sucked by capillary actions into the wall through the grout joints between the tiles (Figure 1).

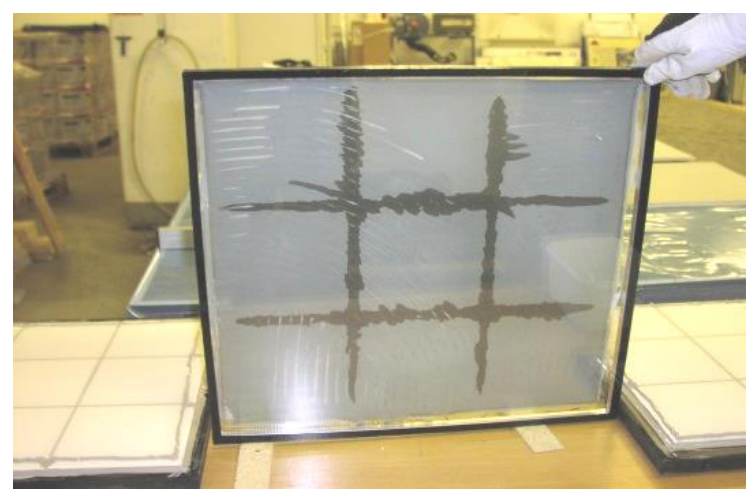

Fig. 1. A section of tiled wall. Water has been sucked to the back through the grout joints. The wall has been exposed to free water for two minutes. [1].

The wall dries through diffusion force. Diffusion is a weaker force than capillary force and therefore the drying takes longer than the soaking of the wall. The result of these differences in tiled walls and floors frequently exposed to free water is an accumulation of water in the layer of the tile adhesive. It is calculated that a tiled wall exposed to water for 15 minutes needs roughly six months to dry out. Therefore, in a bathroom used on a daily basis, free water will always be found behind the tiles in the tile adhesive [1]. Microorganisms need access to water to be able to grow. In general, moulds need a relative humidity (RH) of $75 \%$ at $20^{\circ} \mathrm{C}$ to be able to grow on building materials, according to a review by Johansson et al [2]. At lower temperatures, microorganisms generally require more moisture (higher $\mathrm{RH}$ ). Bacteria require significantly higher levels of moisture than mould fungi. Most species of bacteria need a relative humidity of $>95 \%$ [3]. The tile adhesive itself may contain very small amounts of organic material, but is generally regarded as an inorganic building material. The ceramic tiles are made of burnt clay and are inorganic. The waterproof membrane is, however, made of organic polymers. Water sucked into the wall probably contains small amounts of organic compounds but is also polluted with soap residues and human skin particles. These organic compounds may function as nourishment for the microorganisms. Both cement adhesives and sealants used in wet rooms have a $\mathrm{pH}$ value of $\geq 11$. This basic environment is not optimal for most mould species [4] but does not prevent mould growth. Studies have shown that mould species growing on mortar increases their secretion of acids compared to moulds growing on building materials with lower $\mathrm{pH}$ [5]. Studies have also shown that some mould species are more often found on concrete than on other construction materials [6] and this suggests that these species better manage to grow on basic materials than others.

This study's objective was to examine if microorganisms can grow in this specific environment, namely the interface between the back of a ceramic tile and the waterproof membrane.

\footnotetext{
$\overline{{ }^{*} \text { Corresponding author: gunilla.bok@ri.se }}$
} 


\section{Materials and method}

\subsection{Bathrooms}

Tile samples were taken from 13 different bathrooms. All bathrooms were equipped with a bathtub. An example of a bathroom used in the study is shown in Figure 2. All the bathrooms in the study were $20-21$ years old and had no visible moisture damage. In most bathrooms all the walls were constructed of concrete. A few of the bathrooms' window walls were curtain walls. Bathrooms from five different buildings from the same area were used in this study.

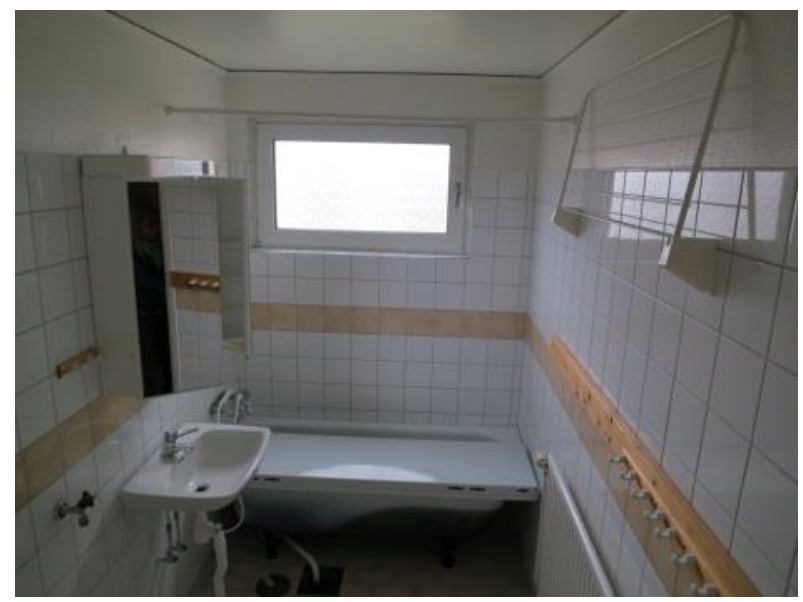

Fig. 2. Typical interior of the bathrooms used in the study.

\subsection{Sampling}

A total of 120 specimens were taken out with a jackhammer. Each sample consisted of tile, cement-based adhesive and waterproof membrane (Figure $3 \& 4$ ). The specimens were taken from the same places and in the same manner in all the bathrooms. Six specimens (A-F) were taken from an area expected to have been frequently exposed to free water (Figure 5) and two specimens (G and R) were taken from places expected not having been exposed to free water (Figure 6a \& 6b).

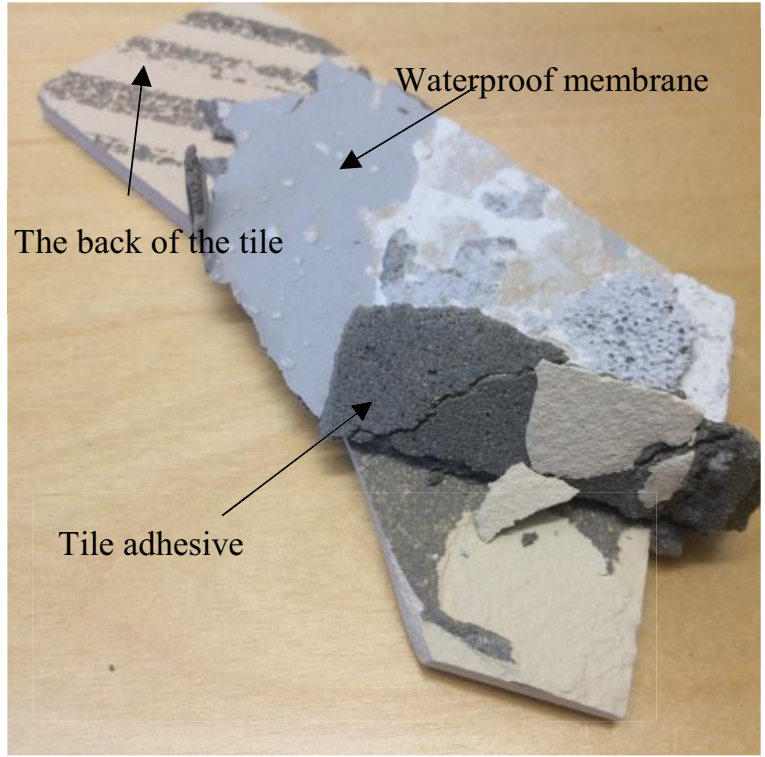

Fig. 3. A specimen taken from a bathroom wall which including all the different components of a tiled surface.

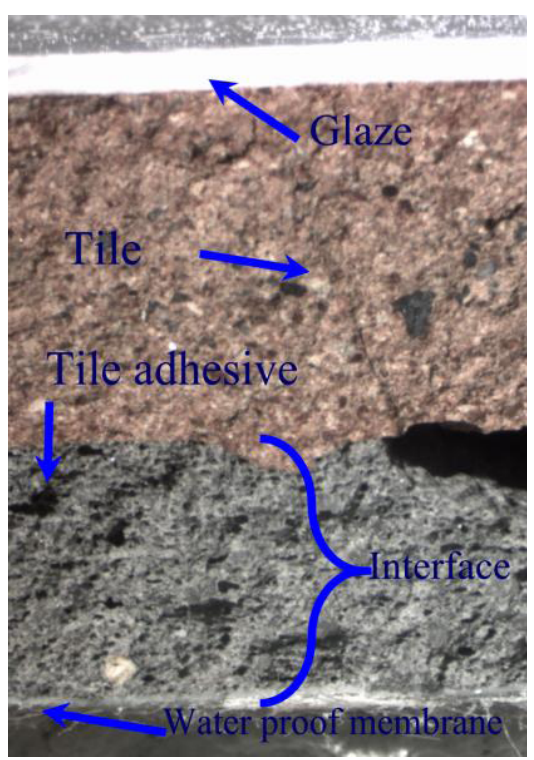

Fig. 4. Magnification of the examined interface between the backside of tile and the sealing layer.

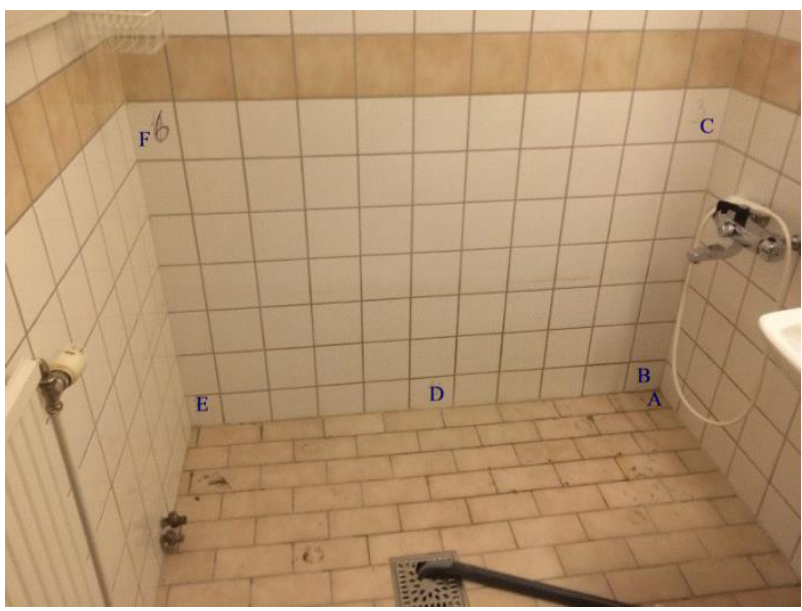

Fig. 5. The places (A-F) from which the specimens were taken after the bathtub has been removed. 

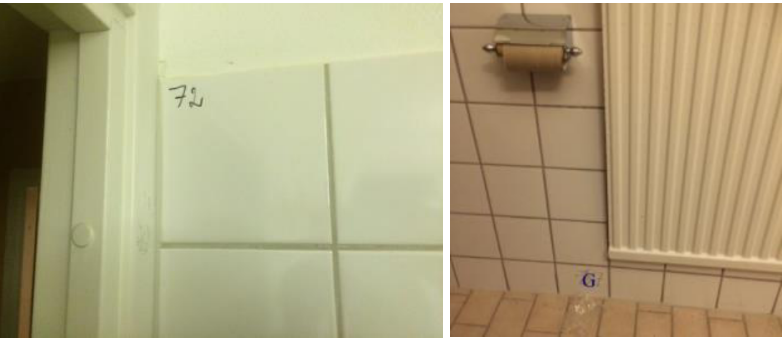

Fig. 6a \& 6b. The places expected not have been exposed to free water. R-specimens were taken in the upper corner next to the entrance doors. G-specimens were taken under the radiator.

\subsection{Microbial analysis}

As a first step a SEM-microscope was used (Hitachi Tabletop Microscope TM-1000) to analyse 13 of the test specimens. Randomly chosen surfaces of the different layers (back of tile, adhesive, and waterproof membrane) were analysed in $1200-7000$ times magnifications. With this method, both bacterial and fungal growth could be detected.

Most of the analysis was performed by optical analysis. In this analysis stereo microscope and light microscope were used in combination. First, the specimens were analysed in $40-60$ times magnification. Second, when microbial structures were found, these structures were picked out with tweezers, placed on microscope slides and further analysed in light microscope in 400 times magnification. The second step was mainly done to confirm that the structures detected in $40-60$ times magnification were of microbial origin. 38 specimens were analysed in this way.

Morphological identification on a genus-level was performed by culturing fungi. Hyphae from the specimens were picked with tweezers and put on Petri dishes containing $2 \%$ malt agar and cultured until structures were developed that could be used for morphological identification.

\section{Results}

Hyphae, conidiophores (Figure 7), and chains of actinomycetes were found, but also individual bacterial cells. Actinomycetes and fungi were found growing both together and separately. Microbial structures were detected in the adhesive (Figure 8), on the water sealing (Figure 9), and on the back of the tile (Figure 10). Of the samples taken from spot A \& B (Figure 5), 8 samples out of 14 had microbiological growth. This part of the bathroom was the area assessed to have been exposed to liquid water to the highest degree. Microorganisms were found on four samples out of eleven on the samples taken from spot C. This spot was considered to have less exposure to liquid water compared to spot A. From spot E \& F one sample out of eleven had microbiological growth. No growth was found on the reference samples taken from spot $\mathrm{G}$ and $\mathrm{R}$.
Table 1. Samples taken from the different spots and analysis result SEM and optical analyses.

\begin{tabular}{|c|c|c|c|}
\hline $\begin{array}{c}\text { Sample } \\
\text { location }\end{array}$ & $\begin{array}{c}\text { Number } \\
\text { analysed }\end{array}$ & $\begin{array}{c}\text { Microbial } \\
\text { occurrence }\end{array}$ & \% occurrence \\
\hline A \& B & 14 & 8 & 57 \\
\hline C & 11 & 4 & 36 \\
\hline E \& F & 11 & 1 & 9 \\
\hline G \& R & 6 & 0 & 0 \\
\hline
\end{tabular}

Filamentous bacteria were detected with SEMmicroscope, not in the optical analyses.

Following genera of fungi were identified, Aspergillus, Aureobasidium, Cladosporium Fusarium, Paecilomyces and Penicillium. Actinomyceter were also cultured on the agar.

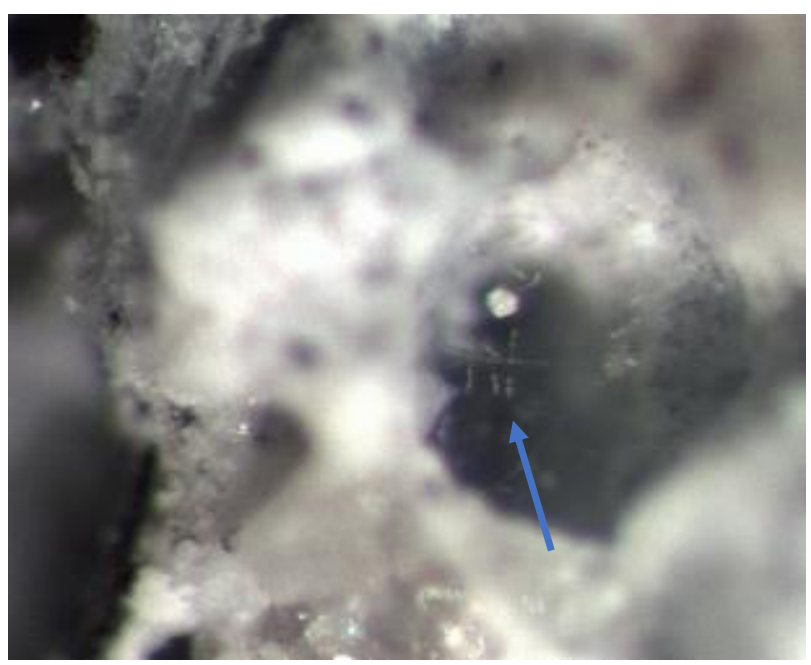

Fig. 7. Hyphae and conidiophores (arrow) in the layer of tile adhesive.

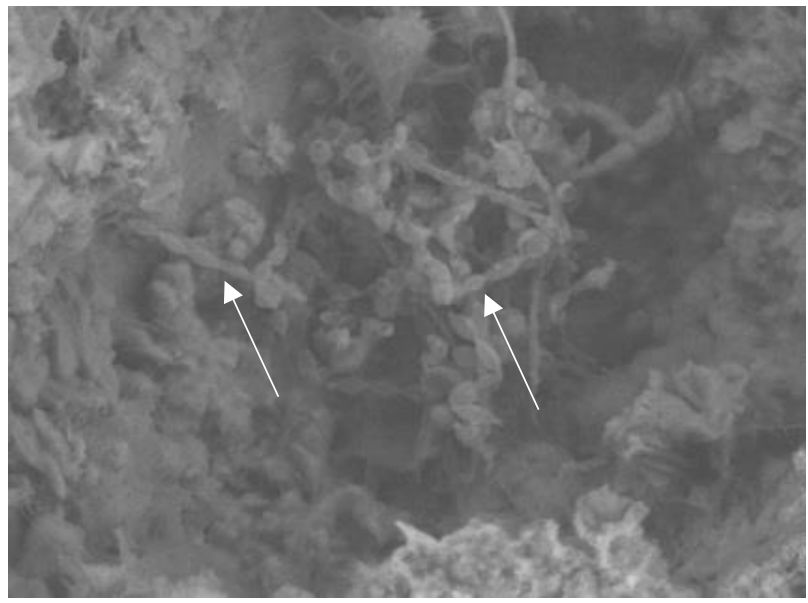

Fig. 8. SEM-picture showing microbial growth in the adhesive layer. Cells are growing in a cavity of tile adhesive. 


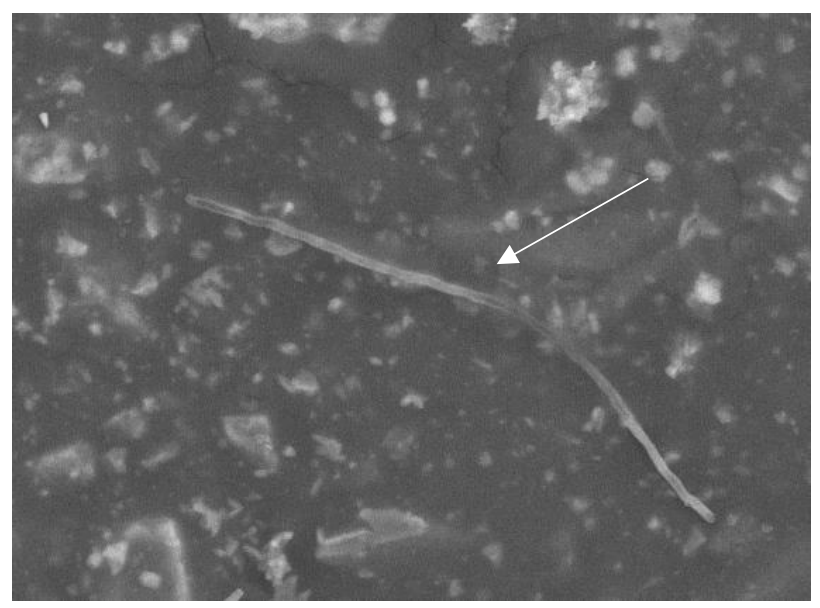

Fig. 9. SEM-picture. Hyphae on a sealing layer.

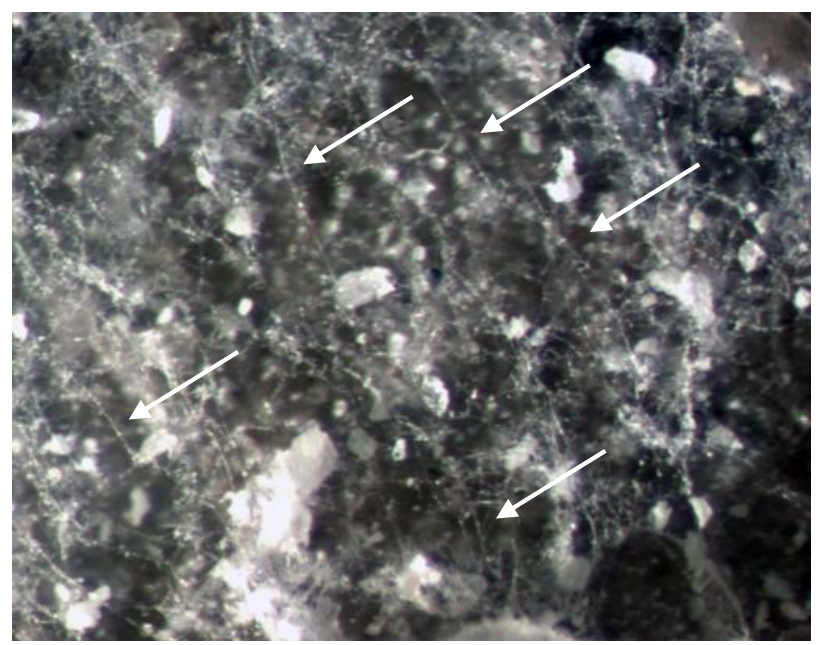

Fig. 10. Hyphae on a tile's back (arrows).

\section{Discussions}

This study shows that microorganisms can grow behind tiles when the environment have a high moisture load. Water is essential for microbial growth, and in addition, water may also add organic compounds, such as soap residues and/or skin particles to this environment and therefore increase the microorganisms' ability to establish a growth. The amount of time it takes for a substantial growth to appear is not investigated because all the bathrooms in this study were constructed in the same year.

As expected, in bathroom areas not exposed to liquid water microorganisms were not found.

Two types of analysis were used supplementing each other. In many cases mould on building materials have a patchy growth and the screening of larger areas increase the opportunity to find this patchy growth. Optical analyses cover relatively large areas and is therefore suitable. One disadvantage with optical analyses when analysing this kind of materials, is the difficulty to quantify the growth. Firstly, the growth often spread through the layer of tile adhesive and was therefore difficult to estimate. Secondly, it was also difficult to separate the different layers. The layers were firmly attached to each other and the areas that could be analysed varied in size depending on how the separation of the different layers succeeded.

SEM-microscope analysis supplemented the optical analysis, since single cell bacteria is close to impossible to detect in 40-60 times magnification. Single cell and filamentous bacteria were both detected in the SEMmicroscope analysis.

This project started the analyses by using SEMmicroscope because we only expected to find bacteria in this specific environment. With the experience of this study, we should instead use optical analyses as a first step. Depending of the result from the optical analyses a SEM-microscope can be used to investigate if bacterial cells also can be found.

Probably the growth on the back of tiles has not a big impact on the air quality in the bathroom because it is probably a limited exchange of air from the back of the tiles to the bathroom.

Due limited resources not all the specimens in this study were analysed.

\section{Conclusions}

Microbiological growth was found in the interface between the tile and the waterproof membrane. Despite relatively high $\mathrm{pH}(\approx 11)$ and the non-organic substrate, mould fungi and actinomycetes were found on the waterproof membrane, on the back of the tiles, and in the tile adhesive. High prevalence of water and temperatures around $20{ }^{\circ} \mathrm{C}$ probably make it possible for microorganisms to establish growth in this, to what it seems, inhospitable environment.

\section{References}

1. Jansson, A., Tätskikt bakom kakel $i$ våtrumsytterväggar. (2006) SP Swe Techn Research Inst: SP Swe Techn Research Inst.

2. Johansson, P., et al., Kritiskt fukttillstånd för mikrobiell tillväxt på byggmaterial kunskapssammanfattning. (2005), SP Swe Techn Research Inst:

3. Flannigan, B. and J.D. Miller, Microbial Growth in Indoor Environments, in Mikroorganisms In Home and Indoor Work Environments. Diversity, health impacts, investigation and control, B. Flannigan, R.A. Samson, and J.D. Miller, Editors. (2001), CRC Press LLC: New York. p. 35-67.

4. Cooke, R.C. and J.M. Whipps, Ecophysiology of Fungi. (1993): Blackwell Scientific Publications.

5. Gutarowska, B., M. Sulyok, and R. Krska, A study of the toxicity of moulds isolated from dwellings. Indoor and Built Environ. (2010). 19(6): p. 668-675.

6. Andersen, B., et al., Associations between Fungal Species and Water-Damaged Building Materials. Appl. and Environ. Microbiol. (2011). 77(12): p. 4180-4188. 